\title{
A new large-bodied theropod dinosaur from the Middle Jurassic of Warwickshire, United Kingdom
}

\author{
Roger B. J. Benson and Jonathan D. Radley \\ Acta Palaeontologica Polonica 55 (1), 2010: 35-42 doi: http://dx.doi.org/10.4202/app.2009.0083
}

Previously undocumented postcranial material from the Chipping Norton Limestone Formation (Middle Jurassic: Lower Bathonian) of Cross Hands Quarry, near Little Compton, Warwickshire represents a new large-bodied theropod dinosaur, distinct from the contemporaneous Megalosaurus bucklandii. Cruxicheiros newmanorum gen. et sp. nov. is diagnosed by a single autapomorphy, the presence of a proximomedially inclined ridge within the groove that marks the lateral extent of the posterior flange of the femoral caput (trochanteric fossa). $C$. newmanorum shows three tetanuran features: widely separated cervical zygapophyses, a swollen ridge on the lateral surface of the iliac blade and an anterior spur of the caudal neural spines. However, due to fragmentary preservation its affinities within Tetanurae remain uncertain: phylogenetic analysis places it as the most basal tetanuran, the most basal megalosauroid (= spinosauroid) or the most basal neotetanuran.

Key words: Dinosauria, Theropoda, Tetanurae, Megalosaurus, Cruxicheiros, Bathonian, Chipping Norton Limestone Formation, England.

Roger B. J. Benson [rbb27@cam.ac.uk], Department of Earth Science, University of Cambridge, Downing Street, Cambridge, UK, CB2 3EQ; Jonathan D. Radley [jonradley@ warwickshire.gov.uk], Warwickshire Museum, Market Place, Warwick, UK CV34 4SA; School of Geography, Earth and Environmental Sciences, University of Birmingham, Edgbaston, Birmingham, UK B15 2TT.

This is an open-access article distributed under the terms of the Creative Commons Attribution License (for details please see creativecommons.org), which permits unrestricted use, distribution, and reproduction in any medium, provided the original author and source are credited. 
Fof Full text $(449.7 \mathrm{kB})$ 